DOI: $10.17805 / g g z .2017 .2 .7$

\title{
Искусственный интеллект и киберпространство
}

\author{
С. В. ЛУКОВ \\ МОСКОВСКИЙ ГУМАНИТАРНЫЙ УНИВЕРСИТЕТ
}

В статье рассматриваются две стороны киберпространства, в рамках которого искусственный интеллект используется как технология самонастройки компьютеров. Одна сторона показывает опасности киберпространста для человека, другая - преимущества, которые человек может использовать в решении транспортной проблемы. Искусственный интеллект и киберпространство, таким образом, открываются для человека теми или иными своими сторонами в зависимости от ценностного выбора человека.

Ключевые слова: киберпространство; искусственный интеллект; ценности; национальная безопасность; андроид; ватцап; Викиликс; автономный автомобиль для райдшеринга; тезаурусный подход

\section{Artificial intelligence and cyberspace}

\author{
S. V. LUKOV \\ MOSCOW UNIVERSITY FOR THE HUMANITIES
}

The article discusses the two sides of the cyberspace in which artificial intelligence is used as a technology of self-tuning computers. One side shows the dangers of cyberspace for persons and second side shows that people can use of artificial intelligence in solving transportation problems. Artificial intelligence and cyberspace, thus, opens for a person with one or other of its sides depending on the value of human choice.

Key words: cyberspace; artificial intelligence; values; national security; Android; WhatsApp; WikiLeaks; autonomous autos for ridesharing; thesaurus approach

\section{BВЕАЕНИЕ}

Кибепространство - неологизм, возникший у американского писателя-фантаста Уильяма Гибсона, создавшего стиль киберпанк и получивший широкое признание своей трилогией «Киберпространство» (Гибсон, 2017). По оценке самого Гибсона, он наблюдал на окраине Ванкувера группу детей, которая старалась не только выиграть на старых игровых автоматах, но как бы войти в них, слиться с ними (Уильям Гибсон. Электронный ресурс). Это и дало жизнь новому слову для обозначения виртуальной сферы компьютерных программ, где нет компьютеров как таковых, но есть их «второй мир», новое состояние людей, перешедших из реального мира в мир несуществующий, но возникший как результат технологической революции.

Аве стороны киберпространства составляют дилемму для человека и человечества. Одна показывает худшие черты этого пространства, вызывает тревогу, а то и панику, опасение надзора неведомых, но все знающих сил, вроде русских хакеров в 2015-2017 гг. Аругая сторона дает надежду, что именно киберпространство одарит человека и человечество такими предметами, которые были в мечтах и фантастических фильмах, но оставались недостижимыми на уровне современных технологий. Сопоставление этих двух сторон киберпространства, в рамках которого искусственный интеллект используется как технология самонастройки компьютеров, является предметом данной статьи. Целью ее является демонстрация того, как «свое» превращается в «чужое» и наоборот в зависимости от субъектной организации знаний, что составляет основу тезаурусного подхода (Ауков В., Ауков Вл., 2008, 2013, 2014). 


\section{КИБЕРПРОСТРАНСТВО КАК АОВУШКА}

Созданная в 2006 г. австралийским журналистом Ажулианом Ассанжем международная некоммерческая организация Викиликс (от «wiki» и «leak», т. е. утечка) и ставшая скандально известной публикацией секретных материалов в 2017 г. начала крупнейшую кампанию по разоблачению ЦРУ США (включая ее глобальную программу взлома электроники по всему миру). Акция Викиликс получила название «Убежище 7» (Vault 7... online). Первая часть документов этой акции под названием «Год Нуля» (8761 файл, в том числе список разнообразных зловредов, вирусов, троянов, десятков 0daу-эксплойтов и полезной нагрузки для них, систем удаленного управления) была опубликована 2 марта 2017 г. (Ibid.) и по объему (числу документов) превзошла публикации Э. Сноудена, публикуемые последние три года. А. Ализар, опираясь на мнение активистов Викиликс, отмечает, что «после такой утечки ЦРУ теряет контроль над большей частью своего хакерского арсенала. Файлы получены из сети с высокой степенью защиты в Центре киберразведки ЦРУ, расположенного в штат Виргиния. На хакерское подразделение Центра киберразведки ЦРУ работает более 5000 человек (судя по количеству зарегистрированных пользователей в системе). Говорят даже, что хакерские ресурсы ЦРУ превосходят их “конкурентов” из АНБ $<$ Агентство национальной безопасности США>. Обладая мощными интеллектуальными ресурсами, әто подразделение разработало широкий арсенал компьютерных программ для компьютерной слежки и шпионажа» (Ализар. Электронный ресурс).

К этому надо прибавить, что «Год Нуля» (《Year Zero») показывает имеющийся у ЦРУ арсенал вредоносных программ и десятки «ноль-дневных» боевых действий против широкого спектра американских и европейских продуктов компании, включая iPhone Apple, Android от Google и Microsoft Windows и даже телевизоры Samsung, которые превращаются в скрытые микрофоны (Vault 7... online).

В этих разоблачениях вскрывается темная сторона киберпространства, его стремление поглотить человека, лишить его свободного выбора. Здесь киберпространство выступает как абсолютное зло.

\section{ПОЗИТИВНАЯ СТОРОНА КИБЕРПРОСТРАНСТВА - \\ СОЗААНИЕ НОВЫХ СРЕАСТВ ПЕРЕАВИЖЕНИЯ}

В то самое время как очевидными становятся ужасы киберпространства, на свет появляются те его стороны, которые как бы порождены искусственным интеллектом, т. е. свойством интеллектуальных систем выполнять творческие функции, которые традиционно считаются прерогативой человека (Аверкин, Гаазе-Рапопорт, Поспелов, 1992).

В каталоге Apple 2017 г. мы обнаруживам 322 модели новейших предметов киберпространства, и среди них мобильные телефоны, ноутбуки, планшеты, персональные компьютеры, «умные» часы и браслеты, наушники, MP3-плееры и т. д. Характерно примечание от сайта: «E-Katalog - каталог описаний и цен на бытовую и компьютерную технику, электронику, товары для дома и офиса» (E-Katalog. Электронный ресурс). Иными словами, речь идет о повседневных предметах, ставших частью тезауруса.

То же можно сказать об операционной системе андроид (англ. Android), созданной для смартфонов, особенно популярных в Великобритании, а также для интернетпланшетов, электронных книг, цифровых проигрывателей, наручных часов и др. Во втором квартале 2014 г. было продано более 295 млн устройств, использующих андройд (Mawston, 2014, online). Значит, к этому времени ежегодное число продаж пре- 
высило 1 млрд. Не случайно для каждой версии андройда, начиная с версии 1.5, подбирается имя какого-нибудь лакомства - кекс, пончик, эклер и т. А., не забыты и KitKat, леденец на палочке, нуга. Таким образом, опять в ход идут знакомые в повседневности и весьма приятные вещи.

Такими же свойствами обладает ватцап (или ВатцАп) - ставшая в последнее время особенно популярной бесплатная (с 2016 г.) система мгновенного обмена текстовыми сообщениями для мобильных и иных платформ с поддержкой голосовой связи, работающая с 2009 г. (последняя версия появилась в 2017 г.). Английское название системы WhatsApp, как подчеркивает Википедия, идет от фразы What's Up? («Что новенького?»), где вместо Up написано App (application, mobile app) - приложение для смартфонов. Опять-таки здесь в новых символах обнаруживается тесная связь киберпространства с усвоенными в повседневности шаблонными фразами.

Обновляется и парк самых ранних игрушек, и из них квадрокоптер (построенный по принципу вертолета) занимает ведущее место. Квадрокоптеры для самых маленьких помещаются на ладони, их можно запускать дома, но его устройство и управление им такое же, как у машин большого размера. Ароны, или беспилотные летательные аппараты, в значительно большей степени ассоциируются с темной стороной того, что называют киберпространством. Таков небольшой шаг от детской игрушки до средства разрушения построенного человеком и уничтожения его самого без какого-либо риска.

Но более всего искусственный интеллект, киберпространство, а с ними вместе и двусмысленные продукты их соединения видны в стремлении сделать человека мобильнее и независимее. Это отразилось в программе американской автомобилестроительной компании Ford по разработке автономного фургона, своего рода квадрокоптера для перевозки пассажиров. Ford вдвое расширил команду специалистов в Кремниевой долине и более чем в два раза увеличил свой кампус в Пало-Альто для того, чтобы создать полностью автономный автомобиль для райдшеринга (т. е. совместного использования частного автомобиля с помощью онлайн-сервисов поиска попутчиков) к 2021 г. (Ford... Электронный ресурс). По мнению Марка Филдса, американского бизнесмена, президента и главного исполнительного директора компании Ford с июля 2014 г., «Следующее десятилетие будет отмечено автоматизацией автомобилей, и мы считаем автономные автомобили столь же значимыми с точки зрения их влияния на развитие общества, как и конвейер Генри Форда 100 лет назад. Мы концентрируем наши усилия на том, чтобы вывести на дороги автономный автомобиль, который будет способствовать повышению безопасности и решению социальных и экологических проблем для миллионов людей, не только для тех, кто может позволить себе автомобили премиум-класса» (Названы... Электронный ресурс).

Рассмотрим подробнее этот проект. Он предполагает, что принципиально новый массовый автомобиль будет соответствовать категории 4 по классификации Сообщества автомобильных инженеров SAE, не будет иметь руля, педалей газа и тормоза. Принципиальная новизна именно в массовости этого автомобиля, ведь его уникальные экземпляры производились компанией более десяти лет назад. В информации об автомобиле есть такое указание: «Ford был первым автопроизводителем, который начал испытывать свои автомобили в Mcity, полномасштабном городе-полигоне, созданном Мичиганским университетом; первым автопроизводителем, который публично продемонстрировал автономный автомобиль, способный передвигаться в условиях снега; а также первым автопроизводителем, протестировавшим исследовательский 
автономный автомобиль в ночное время, в условиях полной темноты, в рамках разработки сенсоров LiDAR» (Ford... Электронный ресурс).

Обращает на себя внимание следующее сообщение: «Ford приобрел расположенную в Израиле компанию, специализирующуюся в области компьютерного зрения и машинного обучения, для повышения квалификации в области искусственного интеллекта и ускорения разработок в сфере компьютерного зрения. SAIPS разработал алгоритмические решения в области обработки изображений и видео, глубинного обучения, обработки и классификации сигналов. Эти разработки помогут автономным автомобилям Ford обучаться и адаптироваться к окружающей их среде» (там же). Очень похожее сообщение встречаем в той же публикации: «Ford имеет эксклюзивное лицензионное соглашение с Nirenberg Neuroscience, компанией в сфере компьютерного зрения, основанной нейробиологом доктором Шейлой Ниренберг, которая раскрыла нейронный код, используемый глазом для передачи визуальной информации в мозг. Это привело к разработке мощной платформы компьютерного зрения, обеспечивающей навигацию, распознавание объектов и лиц, а также другие функции и имеющей множество потенциальных сфер применения. К примеру, она уже применяется доктором Ниренберг для разработки устройства для восстановления зрения у пациентов с дегенеративными заболеваниями сетчатки. Партнерство Ford c Nirenberg Neuroscience поможет привнести человекоподобный интеллект в модули машинного обучения автономного автомобиля Ford» (там же). Это ясные свидетельства того, что новый автомобиль конструируется с применением достигнутого в области искусственного интеллекта и предполагает его (интеллекта) обогащение и развитие за счет внедрения новой машины.

\section{ЗАКАЮЧЕНИЕ}

Аве стороны киберпространства, с учетом использования в нем искусственного интеллекта, показывают, что фантастическая для своего времени идея приобретает со временем все более осмысленные формы по мере ее освоения сферой бизнеса. Пока те или иные идеи не становятся прагматическими и не сулят прибыли в особо крупных размерах, они малопривлекательны и находятся на краю тезаурусов современных предпринимателей, даже если они в доступных формах (например, кино) приняты определенной частью или большинством обывателей, т. е. представителей повседневности, реализующие ее в своих социальных практиках.

Но становясь прагматическими, они, эти идеи, тут же раскрываются с двух своих сторон: одна открывает человеку новые степени свободы, другая наглухо закрывает их. Так тезаурусы неоднозначно отражают картины мира, а тезаурусный подход, опираясь на аксиологию, стремится не искать слабости человека в его освоении мира, а понимать эту двойственность как неизбежный результат разделения идей на «свои» и «чужие», где то, какими будут названы эти идеи и в каких направлениях они будут развиваться уже как технологии, прямо зависит от системы ценностей, которую разделяет тот или иной субъект - носитель субъектной организации знания.

\section{СПИСОК АИТЕРАТУРЫ}

Аверкин, А. Н., Гаазе-Рапопорт, М. Г., Поспелов, А. А. (1992) Толковый словарь по искусственному интеллекту. М. : Радио и связь. 256 с.

Ализар, А. Опубликована коллекция хакерских инструментов ЦРУ // Geektimes [Электронный ресурс]. URL: https://geektimes.ru/post/286702 (дата обращения: 2.04.2017). 
Гибсон, У. (2017) Нейромант. Трилогия «Киберпространство» / сост. А. Жикаренцев. СПб. : Азбука, М. : Азбука-Аттикус. 960 с.

Ауков, В. А., Ауков, Вл. А. (2008) Тезаурусы : Субъектная организация гуманитарного знания. М. : ИзА-во Нац. ин-та бизнеса. 784 с.

Ауков, В. А., Ауков, Вл. А. (2013) Тезаурусы II : Тезаурусный подход к пониманию человека и его мира : монография. М. : Изд-во Нац. ин-та бизнеса. 640 с.

Ауков, В. А., Ауков, Вл. А. (2014) Методология тезаурусного подхода: стратегия понимания // Знание. Понимание. Умение. №1. С. 18-35.

Названы сроки появления серийного автомобиля без руля и педалей [Электронный ресурс]. URL: http://pikabu.ru/story/nazvanyi_sroki_poyavleniya_seriynogo_avtomobilya_bez_rulya_i_ pedaley_4410704 (дата обращения: 2.04.2017).

Уильям Гибсон. О возникновении «киберпространства»// Cyberpunkworld. 2011 [Электронный ресурс]. URL: http://cyberpunkworld.net/news/uiljam_gibson_o_vozniknovenii_kiberprostranstva/2011-06-25-126. (дата обращения: 2.04.2017).

E-Katalog.Каталог Apple 2017 [Электронный ресурc]. URL: http://www.e-katalog.ru/ekbrand.php?idb_=116\&cgi_idsr_ $=67282 \& u t m \_s o u r c e=$ adv\&utm_medium $=$ ya_direct\&utm_campaign $=$ brands-new-ek-ru-msk $\mid 21277863 \& u t m \_c o n t e n t=\bar{k} 50$ id $\mid 010000007024436838$ |cid|21277863|gid|1890039651|aid|2782663999|adp|no|pos|premium2|src|search_none|dvc|desktop|\&utm _term $=\% \mathrm{D} 1 \% 8 \mathrm{D} \% \mathrm{D} 0 \% \mathrm{BF} \% \mathrm{D0} \% \mathrm{BB} \& \mathrm{yclid}=2382801819272745863$ (дата обращения: 2.04.2017).

Ford создаст полностью автономный автомобиль для райдшеринга к 2021 году [Электронный ресурс]. URL: http://www.ford.ru/AboutFord/News/Corporate/2016/Corp_160817 (дата обращения: 2.04.2017).

Mawston, N. (2014) Android Captures Record 85 Share of Global Smartphone Shipments in Q2 2014 // Strategy Analytics: Research, Expert and Analytics [El. Resourse]. URL:https://www.strategyanalytics.com/access-services/devices/mobile-phones/smartphone/smartphones/reports/reportdetail/android-ca ptures-record-85-share-of-global-smartphone-shipments-in-q2-2014\#. WQw3xVXyiUl (дата обращения: 2.04.2017).

Vault 7: CIA Hacking Tools Revealed (El. resourse). URL: https://wikileaks.org/ciav7p1/ (дата обращения: 2.04.2017).

\section{REFERENCES}

Averkin, A. N., Gaaze-Rapoport, M. G. and Pospelov, D. A. (1992) Tolkovyj slovar' po iskusstvennomu intellektu. Moscow, Radio i svyaz'. 256 p. (In Russ.)

Alizar, A. Opublikovana kollekciya hakerskih instrumentov CRU. Geektimes [online] Avaible at: https://geektimes.ru/post/286702 (access date: 2.04.2017). (In Russ.)

Gibson, U. (2017) Nejromant. Trilogiya "Kiberprostranstvo»/ sost. A. Zhikarencev. SanktPeterburg, Azbuka, Moscow, Azbuka-Attikus. 960 p. (In Russ.)

Lukov, V. A. and Lukov, Vl. A. (2008) Tezaurusy: Sub'ektnaya organizaciya gumanitarnogo znaniya. Moscow, Izd-vo Nac. in-ta biznesa. 784 p. (In Russ.)

Lukov, V. A. and Lukov, Vl. A. (2013) Tezaurusy II : Tezaurusnyj podhod k ponimaniyu cheloveka i ego mira : monografiya. Moscow, Izd-vo Nac. in-ta biznesa. 640 p. (In Russ.)

Lukov, V. A. and Lukov, Vl. A. (2014) Metodologiya tezaurusnogo podhoda: strategiya ponimaniya. Znanie. Ponimanie. Umenie, no. 1, pp. 18-35. (In Russ.)

Nazvany sroki poyavleniya serijnogo avtomobilya bez rulya $i$ pedalej [online] Avaible at: http://pikabu.ru/story/nazvanyi_sroki_poyavleniya_seriynogo_avtomobilya_bez_rulya_i_pedaley_4410704 (access date: 2.04.2017).

Uil'yam Gibson. O vozniknovenii «kiberprostranstva». Cyberpunkworld. 2011 [online] Avaible at: http://cyberpunkworld.net/news/uiljam_gibson_o_vozniknovenii_kiberprostranstva/2011-06-25126. (access date: 2.04.2017). (In Russ.)

E-Katalog. Katalog Apple 2017 [online] Avaible at: http://www.e-katalog.ru/ek-brand.php?idb_ $=116 \&$ cgi_idsr_ $=67282 \& u t m \_s o u r c e=a d v \& u t m \_$medium $=$ya_direct\&utm_campaign=brands-newek-ru-msk| $212 \overline{7} 7863 \&$ utm_content $=$ k50id|010000007024436838_|cid|21277863|gid|1890039651|aid| 
$2782663999 \mid$ adp|no|pos|premium2|src|search_none|dvc|desktop|\&utm_term=\%D1\%8D\%D0\%BF \%D0 \%BB\&yclid=2382801819272745863 (access date: 2.04.2017). (In Russ.)

Ford sozdast polnost'yu avtonomnyj avtomobil' dlya rajdsheringa $k 2021$ godu [online] Avaible at: http://www.ford.ru/AboutFord/News/Corporate/2016/Corp_160817 (access date: 2.04.2017). (In Russ.)

Mawston, N. (2014) Android Captures Record 85 Share of Global Smartphone Shipments in Q2 2014. Strategy Analytics: Research, Expert and Analytics [online] Avaible at: https://www.strategyanalytics.com/access-services/devices/mobile-phones/smartphone/smartphones/reports/reportdetail/android-captures-record-85-share-of-global-smartphone-shipments-in-q2-2014\#. WQw3xVXyiUl (access date: 2.04.2017).

Vault 7: CIA Hacking Tools Revealed [online] Avaible at: https://wikileaks.org/ciav7p1/ (access date: 2.04 .2017$)$.

Аата поступления: 10.04.2017 2.

Ауков Сергей Валерьевич - кандидат социологических наук, магистр социальной работы (Германия), заместитель директора Центра социологии молодежи Института фундаментальных и прикладных исследований Московского гуманитарного университета. Адрес: 111395, Россия, Москва, ул. Юности, д. 5. Тел.: +7 (499) 374-75-95. Эл. адреc: sv-lukov@rambler.ru

Lukov Sergey Valerievich, Candidate of Sociology, Master of Social Work (Germany), Deputy Director, Center for the Sociology of Youth, Institute of Fundamental and Applied Studies, Moscow University for the Humanities. Postal address: 5 Yunosti St., 111395 Moscow, Russian Federation. Tel.: +7 (499)374-75-95. E-mail: sv-lukov@rambler.ru

Аля иитирования:

Иуков С. В. Искусственный интеллект и киберпространство [Электронный ресурс] // Горизонты гуманитарного знания. 2017. № 2. URL: http://journals.mosgu.ru/ggz/article/view/464 (дата обращения: АА.мм.гггг.). DOI: 10.17805/ggz.2017.2.7 